\title{
ILEAL GIST - CASE REPORT AND REVIEW OF LITERATURE
}

Haripriya Reddy ${ }^{1}$, Karigalan $K^{2}$, Basawana Gowda ${ }^{3}$, Naga Teja ${ }^{4}$

\section{HOW TO CITE THIS ARTICLE:}

Haripriya Reddy, Karigalan K, Basawana Gowda, Naga Teja. "Ileal Gist - Case Report and Review of Literature". Journal of Evolution of Medical and Dental Sciences 2014; Vol. 3, Issue 06, February 10; Page: 1498-1502, DOI: $10.14260 /$ jemds/2014/2014

ABSTRACT: Gastrointestinal stromal tumors (GIST) are the most common mesenchymal tumors of the gastrointestinal tract (GIT). They can arise anywhere along the gastrointestinal tract. GIST of the small bowel is less common. Clinically, most of the GIST present as GI bleed and rarely with intestinal obstruction. We report here a case of ileal GIST presented with subacute intestinal obstruction.

KEYWORDS: Gastrointestinal stromal tumor; Small bowel; Subacute intestinal obstruction.

MESH TERMS: Gastrointestinal Stromal Tumors; Small Intestine; Intestinal Obstruction.

INTRODUCTION: Gastrointestinal stromal tumors are rare soft tissue sarcomas arising from mesenchymal tissue of GIT. Though account for $<1 \%$ of all GIT tumors, they are most common mesenchymal tumors of GIT. They can arise anywhere along the gastrointestinal tract including stomach, small bowel, large bowel, mesentery, and omentum. GIST often presents with vague symptoms, sometimes GI bleed but intestinal obstruction or perforations are extremely rare presentations.

Here we report a case of subacute intestinal obstruction secondary to ileo-ileal intussusception with ileal GIST as the lead point. This case is being reported for its rare presentation with review of literature on Gastrointestinal stromal tumors.

CASE REPORT: A 64 year old female patient was admitted to our hospital with abdominal pain of 20days duration, vomiting and loose stools of 3 days duration. Patient was never admitted for any complaints in the past.

General examination revealed a pulse rate of $82 / \mathrm{min}$, blood pressure of $120 / 70 \mathrm{mmh}$ with normal temperature. On systemic examination, abdomen was soft, not distended, no mass palpable but mild epigastric tenderness was present. Bowel sounds were sluggish. All blood investigations were within normal limit. Erect x-ray abdomen was normal. Ultrasound abdomen showed doubtful ileo-colic intussusception. CECT abdomen confirmed ileo-ileal intussusception with enhancing mass lesion in the ileum.

Patient underwent laparotomy. Ileo-ileal intussusception with mesenteric lymphadenopathy was seen. Intussusception was reduced, bowel found viable but a tumor of $5 \times 5 \mathrm{~cm}$ was found in the distal ileum as the lead point of intussusception (Fig. 1). 


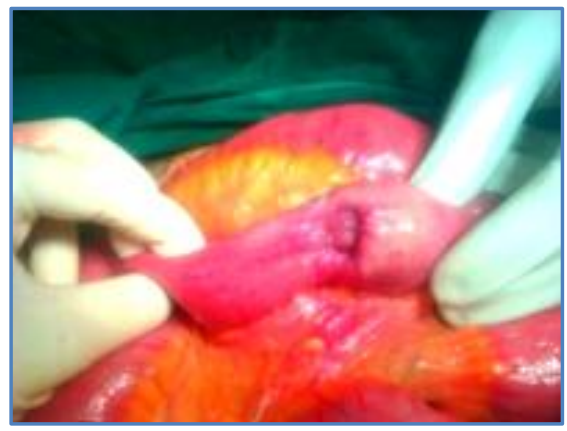

Fig. 1: Intraop ileal tumour

Resection of ileum containing tumor with $5 \mathrm{~cm}$ tumor free margins was done and ileo-ileal anastomosis performed. Mesenteric lymph node biopsy was also performed. Cut section of gross specimen showed soft, fleshy, pedunculated stromal tumor within the ileum (Fig. 2).

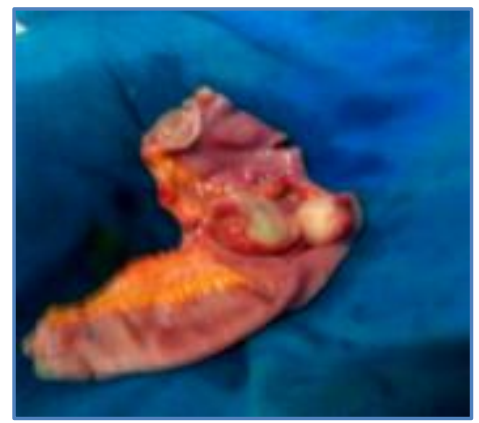

Fig. 2: Cut section of gross specimen

Patient postop recovery was uneventful and was discharged on postop day 7 . Histopathological examination of specimen showed gastrointestinal stromal tumor with tumor free margins and lymph node sections showed reactive changes.

REVIEW OF LITERATURE: Gastrointestinal stromal tumor (GIST) is a mesenchymal tumor of the digestive tract showing lineage differentiation similar to the interstitial cell of Cajal (ICC) and accounts for about $2 \%$ of all GI tract neoplasms ${ }^{1}$.

The increased incidence of GIST in 1995-2003 from 2.1 per million inhabitants to 12.7 per million inhabitants is related to increased understanding of GIST pathobiology and the routine availability of the diagnostic immunohistochemical antibody directed against the CD117 antigen ${ }^{2}$.

GISTs typically present in older individuals and are most common in the stomach (60-70\%), followed by small intestine (20-25\%), colon and rectum (5\%), and esophagus $(<5 \%)$. Benign tumors outnumber the malignant ones by a wide margin. Approximately 70\% of GISTs are positive for CD34, $20-30 \%$ are positive for smooth muscle actin (SMA), 10\% are positive for S100 protein and $<5 \%$ are positive for desmin ${ }^{3}$.

Malignant gastrointestinal stromal tumors are rare, but are more common in the older population, men and Blacks 4 . GISTs are classified as tumors with low- and high-risk of malignancy, depending on tumor size and mitotic count. Tumor site and acute onset are also significant parameters for prognostic purposes 5 . 
Gastrointestinal stromal tumors often present with vague symptoms. Their clinical manifestation as acute abdomen due to obstruction or perforation is extremely rare ${ }^{6}$. Ninety percent of GISTs were detected clinically due to symptoms (69\%) or were incidental findings at surgery (21\%); the remaining $10 \%$ of GISTs were found at autopsy?.

The clinical features can vary depending on the anatomic location, size and aggressiveness of the tumor. Most symptomatic patients have tumors larger than $5 \mathrm{~cm}$ in maximal dimension. In a series of cases with leiomyomas and leiomyosarcoma (without separation of the GISTs), there were three major presentations ${ }^{8}$, GI bleeding (40\%), abdominal mass (40\%) and abdominal pain (20\%). Two-thirds of patients had GI bleeding while 25 to $40 \%$ presented with an intestinal obstruction. Intestinal perforation can also occur uncommonly9.

$\mathrm{CT}$ is essential for evaluating the primary tumor and for accurate staging. Magnetic resonance imaging (MRI) has a comparable diagnostic yield ${ }^{10}$ and lacks radiation exposure. However, CT is preferred initially for screening and staging. CT is better at global evaluation of the abdomen, especially the hollow viscera, than MRI. MRI may be preferred for GISTs at specific sites, such as rectum or liver ${ }^{11}$.

PET can be useful for detecting an unknown primary site or resolving ambiguities from $\mathrm{CT}^{12}$. On upper GI endoscopy, a smooth, mucosa-lined protrusion of the bowel wall, with or without signs of bleeding and ulceration may be seen ${ }^{13}$. A preoperative biopsy is not generally recommended for a resectable lesion in which there is a high suspicion for GIST, and the patient is otherwise operable. However, a biopsy should be done to confirm the diagnosis particularly when metastatic disease is present or suspected. If preoperative imatinib is considered in a patient who has a large locally advanced lesion thought to represent GIST, a biopsy should be done. An endoscopic ultrasound (EUS) guided biopsy (in carefully selected patients and preferably of the primary lesions) is more desirable than a percutaneous biopsy ${ }^{14}$.

Definitive surgery remains the treatment of choice for patients with localized GIST. Complete surgical resection is recommended for small gastric GISTs $<2 \mathrm{~cm}$ at high risk of recurrence based upon EUS appearance (irregular borders, cystic spaces, ulceration, echogenic foci, or heterogeneity in appearance).

For tumours that lack these features, endoscopic surveillance is an option. However, initial therapy with imatinib may be preferred if a tumor is borderline resectable, or if resection would necessitate extensive organ disruption. There is no specific consensus or guideline for the use of neoadjuvant imatinib at this time. However, this could serve as the initial therapeutic intervention, with follow-up at close intervals to ensure appropriate response to therapy. In these situations, early assessment of therapeutic response by FDG-PET scanning could be very valuable to confirm the response to imatinib. After maximal response (usually occurring within 4 to 6 months), definitive surgery could be performed 15 .

Our experience indicates that the site of origin of gastrointestinal stromal tumours with their broad spectrum of clinical presentations may influence both the therapeutic choice (neoadjuvant utilisation of imatinib mesylate) and the surgical treatment (wedge resection vs. enlarged operations) ${ }^{16}$.

A majority (80-90\%) of patients with metastatic disease responds to imatinib or achieves durable tumor growth stabilization with continuous therapy using a daily dose of $400 \mathrm{mg}$ to $600 \mathrm{mg}$. Treatment with imatinib increases survival of patients with advanced disease with a few years and is 
associated with only moderate toxicity. Imatinib is being evaluated as adjuvant treatment following surgery, and other tyrosine kinase inhibitors as treatments of advanced GIST17. Ongoing studies are evaluating the role of imatinib in the preoperative and postsurgical adjuvant settings. Although resistance to imatinib will appear over time, there is reason for optimism that the mechanisms of resistance will be identified and eventually overcome ${ }^{18}$.

CONCLUSION: GIST should always be among the differential diagnosis of an intra-abdominal nonepithelial malignancy. Imaging difficulties impede an early diagnosis. These tumors can present with rare manifestations; sometimes with an unexpected intraoperative finding or an emergency abdominal picture. Surgery remains the mainstay of treatment in patients with localized, resectable disease. Imatinib mesylate is the gold standard for unresectable and metastatic disease. Sunitinib malate (Sutent; SU 11248) is the $2^{\text {nd }}$ generation tyrosine kinase inhibitor recently approved by FDA in 2006 for therapy of GIST patients who failed to respond to imatinib treatment.

\section{REFERENCES:}

1. Kim KM, Kang DW, Moon WS, Park JB, Park CK, Sohn JH, Jeong JS, Cho MY, Jin SY, Choi JS, Kang DY. Gastrointestinal Stromal Tumor Committee; The Korean Gastrointestinal Pathology Study Group. Gastrointestinal Stromal Tumors in Koreans: Incidence and the Clinical, Pathologic and Immunohistochemical Findings. J Korean Med Sci. 2005; 20:977-984. doi: 10.3346/jkms.2005.20.6.977. [PMC free article] [PubMed] [Cross Ref]

2. Goettsch WG, Bos SD, Breekveldt-Postma N, Casparie M, Herings RM, Hogendoorn PC. Incidence of gastrointestinal stromal tumours is underestimated: Results of a nation-wide study. Eur J Cancer. 2005; 41:2868-2872. doi: 10.1016/j.ejca.2005.09.009. [PubMed] [Cross Ref]

3. Miettinen M, Lasota J. Gastrointestinal stromal tumors - definition, clinical, histological, immunohistochemical, and molecular genetic features and differential diagnosis. Virchows Archiv. 2001; 438:1-12. doi: 10.1007/s004280000338. [PubMed] [Cross Ref]

4. Tran T, Davila JA, El-Serag HB. The epidemiology of malignant gastrointestinal stromal tumors: an analysis of 1458 cases from 1992 to 2000. Am J Gastroenterol. 2005; 100:162-168. doi: 10.1111/j.1572-0241.2005.40709.x. [PubMed] [Cross Ref]

5. Versaci A, Macrì A, Ieni A, Terranova M, Leonello G, Saladino E, Speciale G, Famulari C. [Gastrointestinal stromal tumour: our experience]. Chir Ital. 2009 Mar-Apr; 61(2):161-9. Italian. PubMed PMID: 19536989.

6. Efremidou E, Liratzopoulos N, Papageorgiou M, Romanidis K. Perforated GIST of the small intestine as a rare cause of acute abdomen: Surgical treatment and adjuvant therapy. Case report. J Gastrointestin Liver Dis. 2006; 15:297-299. [PubMed]

7. Nilsson BP, Bumming P, Meis-Kindblom JM, Odén A, Dortok A, Gustavsson B, Sablinska K, Kindblom LG. Gastrointestinal stromal tumors: The incidence, prevalence, clinical course, and prognostication in the preimatinib mesylate era. Cancer. 2005; 103:821-829. doi: 10.1002/cncr.20862. [PubMed] [Cross Ref]

8. Chou FF, Eng HL, Sheen-Chen SM. Smooth muscle tumors of the gastrointestinal tract: analysis of prognostic factors. Surgery. 1996;119(2):171-177. doi: 10.1016/S0039-6060(96)801656.[PubMed] [Cross Ref] 
9. Pink D. et al. Severe hypoglycemia caused by paraneoplastic production of IGF-II in patients with advanced gastrointestinal stromal tumors: a report of two cases. J Clin Oncol. 2005;23(27):6809-6811. doi: 10.1200/JC0.2005.02.4828.[PubMed] [Cross Ref]

10. Scarpa M. et al. A systematic review on the clinical diagnosis of gastrointestinal stromal tumors. J Surg Oncol. 2008;98(5):384-392. doi: 10.1002/jso.21120.[PubMed] [Cross Ref].

11. Lamba G, Gupta R, Lee B, Ambrale S, Liu D. Current management and prognostic features for gastrointestinal stromal tumor (GIST). Exp Hematol Oncol. 2012 Jun 18;1(1):14. doi: 10.1186/2162-3619-1-14. PubMed PMID: 23210689; PubMed Central PMCID: PMC3514103.

12. Demetri GD. et al. NCCN Task Force report: management of patients with gastrointestinal stromal tumor (GIST)--update of the NCCN clinical practice guidelines. J Natl Compr Canc Netw. 2007;5(Suppl 2):S1-S29. quiz S30. [PubMed]

13. Pidhorecky I. et al. Gastrointestinal stromal tumors: current diagnosis, biologic behavior, and management. Ann Surg Oncol. 2000;7(9):705-712. doi: 10.1007/s10434-000-0705-6.[PubMed] [Cross Ref]

14. Avritscher R, Gupta S. Gastrointestinal stromal tumor: role of interventional radiology in diagnosis and treatment. Hematol Oncol Clin North Am. 2009;23(1):129-137. doi: 10.1016/j.hoc.2008.11.002. ix. [PubMed] [Cross Ref]

15. DeVita VT, Lawrence TS, Rosenberg SA. DeVita, Hellman, and Rosenberg's cancer: principles \& practice of oncology. 9. Wolters Kluwer Health/Lippincott Williams \& Wilkins, Philadelphia; 2011. p. 2638. xlvii.

16. Pacelli F, Rosa F, Papa V, Tortorelli AP, Sanchez AM, Covino M, Sofo L, Doglietto GB. [Gastrointestinal stromal tumours: a broad spectrum of clinical presentations]. Chir Ital. 2007 Nov-Dec;59(6):771-9. Italian. PubMed PMID: 18360981.

17. Joensuu H. Gastrointestinal stromal tumor (GIST) Annals of Oncology. 2006;17:280-286. doi: 10.1093/annonc/mdl274. [Cross Ref]

18. George S, Desai J. Management of gastrointestinal stromal tumors in the era of tyrosine kinase inhibitors. Curr Treat Options Oncol. 2002 Dec;3(6):489-96. Review. PubMed PMID: 12392638.

\section{AUTHORS:}
1. Haripriya Reddy
2. Karigalan K.
3. Basawana Gowda
4. Naga Teja

\section{PARTICULARS OF CONTRIBUTORS:}

1. Assistant Professor, Department of General Surgery, P.E.S.I.M.S.R, Kuppam.

2. Assistant Professor, Department of General Surgery, P.E.S.I.M.S.R, Kuppam.

3. Professor, Department of General Surgery, P.E.S.I.M.S.R, Kuppam.
4. Post Graduate, Department of General Surgery, P.E.S.I.M.S.R, Kuppam.

\section{NAME ADDRESS EMAIL ID OF THE CORRESPONDING AUTHOR:}

Dr. Haripriya Reddy, No. 202, Second Floor, Staff Quarters,

P.E.S.I. M.S.R, Kuppam, A.P.

E-mail: haari_priyaa@yahoo.com

Date of Submission: 16/01/2013.

Date of Peer Review: 17/01/2014.

Date of Acceptance: 28/01/2014.

Date of Publishing: 08/02/2014. 